\title{
Applications of composite flour in development of bakery products
}

\section{S.D. Dalal and H.P. Bobade}

See end of the Paper for authors' affiliation

Correspondence to :

\section{S.D. Dalal}

Department of Agricultural Engineering, Maharashtra Institute of Technology, Aurangabad (M.S.) India Email : dalal.sd001.sd@gmail. com
- Abstract : In India, bakery industry is considered as one of the major part of food processing industry. Generally baked products such as bread, biscuit, cookies, muffin, ruskare more popular because of their ready to eat, easily available and preferable good shelf life. Baked products are third most important components of staple diet. The main aim of incorporation of oat and soya flour with wheat flour is to satisfy the increasing demand of a healthy diet. Wheat flour is major ingredient in baked goods, it is also rich protein content. Soya flour have a dominant position due to presence of high quality proteins and balanced amino acid Soya rich in calcium, vitamins A, D, B, and C. Oat also a rich source of dietary fibre helps in digestion, phytochemicals, lipids.oat also good source of vitamin $\mathrm{E}$ and pantothenic acid. Use of oat flour during preparation helps to improve the structure, taste, aroma and nutritive value of bakery products. The incorporation of such soya and oat flour with wheat flour at desired quantity susceptible of baking provides a healthy and nutritionally rich diet in breakfast. Multigrain addition of such flour can contribute health benefits such as healthy digestive system, potentially lower fat and highly nutritional.

- Key words : Baked product, Staple diet oat flour, Soy flour, Protein, Lipids, Vitamins, Dietary fibre

- How to cite this paper : Dalal, S.D. and Bobade, H.P. (2018). Applications of composite flour in development of bakery products. Internat. J. Agric. Engg., 11(Sp. Issue) : 65-69, DOI: 10.15740/ HAS/IJAE/11.Sp. Issue/65-69. 